\title{
Is Fat the Only Feminist Issue? Connecting Constructivism to Feminist/Social Inequalities Approaches
}

\author{
Nada Dimcovic \\ Private practice, Belgrade, Serbia
}

\begin{abstract}
Constructivism, as a relatively new and not widely known school of psychotherapy, is becoming more popular due to the influence of some of its concepts on the new developments in dominant psychological modalities. I will make an effort to demonstrate conceptual similarities between constructivism and feminist/inequality approaches to psychotherapy, via a study of women with eating disorders. The usefulness of theoretical assumptions from personal construct psychology/constructivism in understanding eating disorders is well demonstrated. The main contribution of constructivism, we believe, is the idea of human agency and a quest for control. While theory and practice in psychotherapy predominantly work with the individual's ways of construing the past, present and future, social constructionism and inequality approaches emphasize the influence of culture. We are discussing the idea that the main issues of compulsive eating and body/food/weight obsession are rooted in the social inequality of women. However, the story does not end there... Concepts from feminist/inequality approaches may, we believe, enrich constructivism, and make it better suited for understanding the hierarchies of power that form the dominant discourse.
\end{abstract}

Keywords: constructivism, feminist therapies, eating disorders

\section{Personal Construct Theory/Therapy and Constructivism(s)}

When George Kelly first published The Psychology of Personal Constructs in 1955, he offered an image of man as a scientist, proactive rather than reactive, thus emphasizing human agency and choice. Also, he claimed that the person is in permanent motion; construing of self, others and the world is continuously tested for confirmation/disconfirmation with an aim to anticipate events. People develop a personal construct system, which consists of hierarchically connected dimensions of meaning that are bipolar. Furthermore, Kelly developed a number of concepts that describe strategies; the most basic of them being tightening and loosening in construing. Tightening and loosening can be observed in any individual engaged in creative or problem solving activity; they are also major therapeutic tools, as facilitating one and another alternately helps the client to achieve psychotherapeutic change. In addition, disorders in construing may be defined by extreme reliance on one or the other strategy.

However, Kelly's theorizing and therapy were mainly focused on the individual. New understanding and extensions of PCP (personal construct psychology) may be found in Procter (2009). Procter views constructs as perceptual, emotional, and motivational avenue for movement. Although the focus is still on the individual, in

Nada Dimcovic, Dipl. Psych. (psychology), Ph.D., clinical psychologist, private practice. 
his extension of basic theory, Procter introduces the construct as a narrative, as it subsumes or makes sense of events across time. "A construct carries a story and a story communicates one or more constructs" (Procter, 2009 , p. 4). While being personal, a construct is also situational, social as well as interactional.

In his writing on family therapy (1996), this author speaks about the wider and historical interpersonal context, even though the construct is, according to PCP, "anything but personal". He suggests the move from individual to relational construing, while encouraging awareness of how the family members construe their relationships.

PCP is a forerunner of what has been developed into a family of postmodern therapies, i.e., constructivism(s). Similarities and differences between PCP and constructivism are well addressed by Raskin, Weihs, and Morano (2005), Procter (in press) and Pavlovic (in press) and I will not repeat the arguments here. In practice, $\mathrm{PCP}$ and the family of constructivist therapies, including social constructionism and narrative therapies, have many points of convergence. Thus we believe, without much further analysis, that PCP can be classified as a member of a larger constructivist family.

What is new that post-modern approaches bring in? These approaches reject the idea of stable and knowable reality, introducing the concept of multiple realities that are based on individual, social and temporal factors. Also, language and all other symbolic acts "represent a matrix of meaning that actually constitutes, rather than merely reflects, the reality in which one positions oneself" (Neimeyer \& Raskin, 2000, p. 5).

While constructivists focus on experiential exploration of the processes of self-construction with an emphasis on individuality, social constructionism focuses on social origins of meaning, claiming that a person is determined by the ways personhood is conceptualized in societies. Basically, the proponents of this school claim that both identity and disorder are socially constructed.

One of the most prominent figures in social constructivism, Gergen (2011) introduces the idea of socially constructed reality by expanding the construct system to formatting the identity (personhood) through interaction. He speaks of multiple identities as well.

The process of world construction is taking place wherever people are in communication, and in every relationship there are multiple traditions coming into context, creating new formations of expression. There are also conflicts among traditions that continuously threaten theirexistence. Thus, if you move from the context of the family, to a friendship group to a classroom, to the athletic field, to a place of worship, and so on, you will continuously shift in the kinds of realities and values thatare central. You will also import the realities and values central in one context into another, and this may yield creative combinations.... (Gergen, 2011, p. 50)

Further, Gergen interprets Foucault's ideas on distribution of power in social relationship, pointing at the idea that people willingly subdue themselves to subtle forms of power (Foucault, 1978) that are part of tradition and our highly praised institutions.They will be found in education systems, scientific work, professions, legislation... We live with those regulations; the process which he called cultural disciplining was described by Foucault as power/knowledge in vasion.

Here I am giving only a short presentation of theories that will help us understand some specific clinical problems. It is my intention to show how as omewhat different framework may change the focus in everyday practical work of psychotherapy.

\section{PCP on Conceptualizing and Treating Eating Disorders}

PCP has been used for understanding and treating eating disorders for decades. 
One of the main findings on eating disorders from the PCP perspective is the apparently poor balance between tightening and loosening, numerous personal construct psychology studies assumed a more limited, less multidimensional construct system in people with eating disorders, with much stronger evidence for anorexia (Button, 1993). It was less clear for bulimia, as there are several sub-types with a different clinical picture, etiology, response to psychological therapy and prognosis. However, this theoretical perspective highlights some common factors in eating disorders .

What are these common factors, or main issues that are being addressed in psychotherapy informed by this perspective?

\section{Impulsive and Acting out Behavior}

Here, PCP refers to the fact that binge eating can be both "premeditated" and an "impulsive" act. As Kelly duly noticed, "Impulsivity is a form of control, which is preceded by a relatively short period of circumspection" (Kelly, 1991, p. 260). It is possible to find that "acting out" serves to control invalidation and resulting anxiety and depression. Why is this happening in bulimia?

Impulsive action provides a structure and thus controls anxiety. A person... "may construe impulsively to bring some semblance of structure to bear upon his problems" (Kelly, 1991, p 387). It is believed that specific act of overeating resolves uncertainty, fills in the void and "numbs" unpleasant (and painful) emotions.

Bulimia may also be seen as "acting out" of a desperate need for a specific form of satisfaction. What does the bulimic clients' behavior communicate? The need for food is one of the most basic needs and it is safe to assume that it was construed at the pre-verbal levels. The connection between food and need to be loved has been widely demonstrated both in the literature and in clinical practice. Here, one can explore a person's construing of love, protection, safety and reward. It may emerge that at the lower level of awareness food is equated with love.

\section{Faulty Control}

Very probably, therapy will start with elaborating the symptom, as it is usually the main reason for seeing a client and quite often the most urgent theme to work on. Bulimic women will report that they are out of control while overeating. Soon, both the client and the therapist discover that there is also the feeling of "being in control" while overeating. The person who overeats in the evening is giving herself satisfaction after the long day at work and is self-reliant while doing so (Winter \& Button, 2010).

\section{The Function of Dysfunctional Behavior}

An exploration of the multiple meanings of bingeing, including construing of control, is presented by using the Tchudi's ABC model (Tchudi, 1997). We asked our clients to list advantages and disadvantages of bingeing, and of the advantages and disadvantages of stopping. The following is a composite of different clients' responses.

The model is a structured way to explore the meaning of a symptom, with an idea that thesymptom serves a particular function. Historically this was the way to control anxiety, to impose control, to structure time, and to provide satisfaction of some basic need.

There are other areas that this approach suggests should be explored with the client, such as fragmentation, dissociation, self-harmbehavior, sociality and sense of self (Dimcovic \& Winter, unpublished manuscript). 


\begin{tabular}{|c|c|}
\hline The problem & Want to achieve \\
\hline A1. Episodes of overeating & A2. Stop overeating \\
\hline $\begin{array}{l}\text { B1. Disadvantages } \\
\text { Feeling guilty, ashamed, bad } \\
\text { Disgusted with vomiting } \\
\text { Moving in the narrow circle } \\
\text { Isolating myself; feeling isolated } \\
\text { Not having time/energy to do things that I would like to do }\end{array}$ & $\begin{array}{l}\text { B2. Advantages } \\
\text { Feeling good about myself; respect myself (finish with guilt and } \\
\text { shame) } \\
\text { Organize life better } \\
\text { Going out more } \\
\text { Enjoying the company of others } \\
\text { Enrolling the university course }\end{array}$ \\
\hline $\begin{array}{l}\text { C1. Advantages } \\
\text { Feel satisfied } \\
\text { Feel in control } \\
\text { Feeling "numb"; almost like anaesthetising myself } \\
\text { Forget what was wrong during the day } \\
\text { Not dependent on anyone else but myself } \\
\text { I can hide } \\
\text { Filling in the "hole" (an empty space inside) }\end{array}$ & $\begin{array}{l}\text { C2. Disadvantages } \\
\text { Would lose fast satisfaction } \\
\text { Anxious, tense, depressed } \\
\text { Not knowing what to do/how to relate } \\
\text { Fear of new activities, people } \\
\text { "Will miss bit of myself" }\end{array}$ \\
\hline
\end{tabular}

\section{How Is It That One Develops an ED (Eating Disorder)?}

In the majority of cases, it starts with the need to be attractive and attractive means "thin" (which is socially imposed). In an effort to keep oneself at the weight that is not natural for one's body, one may develop binge eating and purging. Gradually, body appearance and food become the main focus of attention and action, and this means constriction and lack of investment in the interpersonal world.

Why is control focused on body shape/weight in ED?

To start with the simplest truth: There is a higher level of concern about appearance in the female population. Slim is good, fat is bad. Dieting and exercise are the must.

Although Kelly did not deny social factors in development of constructs, he did not elaborate on them in detail. As already said, PCP in its original form is an approach that focuses on the individual.

Pavlovic (in press) writes about compatibility of PCP and constructivism, introducing the concept of person-in-discourse, which takes into account social aspects in construing.

In discursive psychology, the metaphor of construction refers to the idea of discourses as socially available resources, some of which are more dominant than others because they reproduce power relations and give support to institutions.

One of the implications of person-the-discourse-analyst metaphor is bringing closer the basic idea of exploring and transforming meaning to ideas of power, institutions and resistance. In other words, this view allows us to explore how powerful cultural images are incorporated in our experience of ourselves. (Pavlovic, in press, p. 12)

Following this line of thinking, the much used PCP idea of human behavior as testing hypotheses and experimentation may be alternatively construed as dialogue and negotiation, writes Pavlovic (in press).

For our discussion here, we need concepts that explain withdrawal from valued social roles and social power in women with ED. These are provided, in my opinion, by feminist therapies.

\section{Feminist Therapies: From Susie Orbach to Laura Brown}

Susie Orbach (1978), a feminist psychotherapist, connected the woman's role in patriarchal culture with eating disorders.

Fat is a social disease, and fat is a feminist issue. Fat is not about lack of self-control, or lack of will-power, Fat is about protection, sex nurturance, strength, boundaries, mothering, substance, assertion and rage. It is a response to inequality of sexes. (Orbach, 1978, p. 28) 
In a patriarchal culture, all cultures are patriarchal, claims Orbach, the mother tries to hold back the daughter's desires to be a powerful, autonomous, self-directed and productive human being. What she should be is sexually attractive, as women will always compete for men's attention; they are not supposed to compete with men. The final aim for girl is to secure social position via a man, that is, a husband.

What comes next is the role of wife and mother. Broadly, these roles assume that everyone else's needs come first. She will have to take care of children, a husband, sometimes her elderly parents... This is supposed to be natural and inevitable. Her role in society is a role of "service worker", which is seen outside the production process and therefore devalued. Her emotional needs are not fulfilled; therefore, compulsive eating fills up the empty space. Finally, "being fat" means that she had given upon the role of the attractive woman, as she is not in the game anymore. It is a form of resistance to imposed standards of society. Fat, real or imagined, is her protection from being seen and treated as as exual object, with all other qualities ignored. A woman must deny her own sexuality in order to be seen as a person, says Orbach.

For those who followed the feminist approach, this was a rather well-known description of woman's role in society. Some may claim that it is out of date. Is it any different today? In many instances, it is different, but this old game of trade-off between sexual attractiveness (women) and social power (man) is still on. The same also goes for the role of mother as a provider and the one who organizes the household, works for the family, and quite often holds a (low-paid) job to add to the family income.

In a number of publications, another feminist therapist, Laura Brown, claims that feminist therapy moved from sole focus on women and gender to a more inclusive model of practice for working with all people.

The same author provides some defining parameters that describe FT (feminist therapies), such as,

(1) FT is a philosophy of psychotherapy, not a prescription of techniques;

(2) FT subverts patriarchal dominance at the subtle and powerful levels as it is internalized and personified in the lives of therapists, clients, colleagues and communities;

(3) Generally, patriarchy leaves its psychological marks in the form of distortions and limitations to everyone's capacity for well-being and personal power (both men and women);

(4) the first and most important "client" of feminist therapy is the culture. (Brown, 1994, 2010)

Patriarchy is incorporated in every aspect of our lives, claims Brown. The societal rules and regulations can (and obviously should) be recognized in contexts of wider society, in the context of culture, that narrow down to community and family. Finally, they become internalized and felt as part of self.

It is accepted that there is no single, unified theory of feminist therapy but different, although overlapping, perspectives.

The best way to describe the contribution of feminist therapies to the wider field is to start with FM (feminist therapies) key concepts, which include: creation of feminist consciousness; development of egalitarian relationship; and empowerment of the client.

Creation of feminist consciousness is where it all started. FT draws attention to all, open and subtle forms of disempowerment in all societies. One can recognize discrimination of marginalized social groups in the academic world, forensic practice, legislation, and obviously communities and families. The FM describe the way academic psychology developed the concept of the healthy, functional individual based on research conducted mostly on male, middle class, white, young persons. This has become the norm. It was supposed that the white man's life was life. Marginalized groups are women, people of color, poor, people of "wrong" sexual orientation, disabled... 
A nice illustration of what it means to be a man in patriarchy was provided by Pantony and Caplan (Caplan, 1995; Pantony \& Caplan, 1991; as cited in Brown, 2000, p. 303).

The two authors reportedly suggested a diagnosis of DDPD (delusional dominating personality disorder) with some of the criteria as follows:

Inability to establish and maintain meaningful interpersonal relationships... Inability to identify and express a range of feelings in oneself (typically accompanied by an inability to identify accurately the feelings of other people).... Inability to respond appropriately and empathically to the feelings and needs of close associates and intimates (often leading to misinterpretation of signals from others)... Tendency to use power, silence withdrawal and/or avoidance rather than negotiation in the personal or interpersonal conflict or difficulty... The presence of any of the following delusions: a. delusion of personal entitlement to the services of $i$. any woman with whom one is personally associated, ii. females in general or males in general iii. both of the above: b. the delusion that women like to suffer and be ordered around, and c. delusion that physical force is the best method of solving interpersonal problem; $d$. the delusion that sexual and aggressiveimpulses are uncontrollable in i. oneself, ii. males in general, od iii. Both; e. the delusion that pornography and erotica are identical; f. the delusion that women control most of the world's wealth and/or power but do little in the world's work; g. the delusion that existing inequality in the distribution of power and wealth are the product of the survival of the fittest and therefore allocation of greater social and economic rewards to the already privileged are merited. (Note; the simultaneous presence of several of these delusions in one individual is common and frequently constitutes a profoundly distorted belief system) (Caplan, 1995, pp. 170-171; Pantony \& Caplan, 1991, as cited in Brown, 2000, p. 303)

Caplan wrote that her proposal was serious, but it hasn't been taken seriously by the revision committee for the DSM-IV in 1991. Only a few years earlier, the proposal for self-defeating personality disorder (mostly women) had been accepted by the same body...

Sounds familiar? It does for me. If APA rejected a "macho personality disorder", try this in Italy, or my country of origin, Serbia?

I do not believe the proposal was serious. FTs have numerous objections to the use of a DSM classification, and therapists of this orientation use it only when it is absolutely necessary. However, it was a good way to show, very graphically, how some behaviors can be seen not as a kind of norm. Both men and women are victims of internalized patriarchal values... according to FT.

The egalitarian relationship in psychotherapy is the next big issue. Even if we move from a picture of a mature, knowledgeable therapist, a man of authority, who treats the younger, immature female, we still create a situation of inequality of power in the psychotherapy room. White middle-class therapists should become aware of inequality issues. FTs even suggest that thetherapist has to tell the client of her/his religious/spiritual beliefs, sexual orientation, etc.. A less radical form of this is found in postmodern therapies, which claim that we have to understand our clients and their point of view to recognize the internal logic that does not always have much to do with our (therapists) logic, or any rational explanation of their motives or their behavior.

Empowerment of the client is more obvious. FTs teach their clients that dysfunctional behavior might be seen as the best response to the situation at the time. Some of the "pathology", like self-harm behavior, may be seen as being the only way to cope with difficulties imposed by the other; dissociation might have been the only way to cut off experience that cannot be tolerated.

Suyemoto and Kim (2005), feminist therapists, come even closer to social constructionism by introducing the idea of multiple identities.

We believe that challenge for multicultural feminist therapists dedicated to social justice is not only to understand 
how these environments affect the individuals (and vice versa), but also to understand how these environments interact within, and depend upon, each other to create meaning and sustain health. (p. 10)

Because the therapy is a co-constructed process, the therapist's own identity actively affects the conduct of therapy and the identities that are co-constructed for the client within therapy. If the therapist is the guide through the terrain of multiple socially co-constructed statuses and identities, then the therapist's own knowledge of that terrain (including the terrain that has not been personally salient in the therapist's own life) becomes of great importance. (Suyemoto \& Kim, 2005, p. 33)

In practice, the therapist offers an invitation to transformation, where she/he may use a wide range of strategies, as long as the main principles of egalitarianism and analysis of power are followed. The protagonists of the approach talk about an integrative model of practice, meaning that they are open to other approaches, as long as the focus of therapy is on the above mentioned. From this perspective, there is much to be said for the area of mental health problems in general, and special groups of people in particular. The fact that ED people (mostly women) give upon investing in socially valued roles and power is best explained by the roles that women were cast into throughout history. Even when the focus of our efforts is an individual, we should leave space for understanding social influence (social status, ascribed characteristics, such as sex, race...) as it may be responsible for the presenting problem.

\section{How Do We Connect These Approaches?}

We started with presenting PCP for treating ED, to serve as an introduction to work with this client group. PCP developed conceptual tools for understanding human distress and the ways to cope with it. A particular set of tools was developed for understanding people with ED, including explanation of impulsive behavior, some areas of faulty control, the ways in which people suffering from ED construe rewards vs. invalidation. PCP also addresses dependencies, which are seen on the continuum from undistributed to distributed dependencies. The approach offers useful tools for understanding and treating people with this disorder, but we found a problem with the focus on the individual, without seriously taking into account the social origins of the disorder.

Next we introduced constructivism, a meta-theory that claims that "reality" is socially invented, with a specific focus on social constructionism. It develops tools for understanding the effects of the rules that are socially invented and internalized, and way in which they regulate the behavior of individuals and groups.

The fact that ED affects mainly women highlights the need for taking feminist approach into consideration.

The main theme of those who represent this approach is the oppression of women in patriarchal societies. Women are de-valued, their voices not heard, their distress very much silenced. In this tone, feminists argue that "private is political" meaning that private distress has to be made public in order to produce changes. The question of power distributions has also been raised and elaborated upon. People who belong to marginalized groups (women, people of color, poor, gay, disabled, old) are clearly underprivileged; they have less access to status and power, including money. Here, the analysis has moved from theory and practice that address women's oppression - towards the practice that applies to all people.

At what point do these different approaches connect? What can they offer each other?

Both approaches have a lot of criticism for DSM, although both accept that it is sometimes necessary as the way to communicate with the wider professional community.

Both work with the idea that "reality" is socially constructed, and demonstrate how to work on transformation/deconstruction of the aspects of "reality" that hold the person down. 
Also, the meaning of symptom is similarly construed in both approaches: It is the person's way to solve some problems, to satisfy some of her needs, no matter how dysfunctional it may seem.

Humans are seen as active, rather than responsive beings. Agency is one of the main concepts in constructivism, whereas FT speaks about human response to adverse circumstances, either in the form of dysfunctional behavior, or in the form of a healthy protest. Both provide similar perspectives for the therapist whose role is to help clients to use their energy in the more appropriate ways.

Generally, constructivism gives a rich meta-theory that marks individual ways of construing the world, based on experiences and making way to anticipations. The authors introduce the idea of complex, multiple realities, and human construing of "reality" via language.

Feminist therapy promotes the idea of social inequality, of the place women had (and still have) in patriarchal societies. This is elaborated through details that provide a good "map of the terrain".

An important point raised by FT: Some situations in which people are stuck are not a choice.

I am not providing a thorough analysis of the philosophical roots of constructivism, neither am I giving a detailed history of thefeminist movement here. The focus of this paper is the realization that we need both: concepts that describe symptoms of distress in women (PCP), a theory of socially constructed reality (constructivism) and the specific map of the terrain provided by feminists' teaching about the hidden signs of patriarchal dominance involved inevery aspect of life.

Therefore, I believe that these approaches can be put together in order to achieve a more comprehensive view of the human conditions and, particularly, human distress.

\section{On Reflection}

After discovering feminists' writings, rather late in my professional life, I may say that I have been doing feminist therapy for a good part of my life. My choice has always been to establish an egalitarian relationship with the client, being at the same time aware of inequality in terms of power. Empowering a person, that is, helping her/him to become aware of her/his strengths was also one of the main issues. The only thing relatively new to me was "consciousness raising", as I was only partially aware of many forms of oppression that are part of our everyday life.

As to the question when this theorizingis relevant, I will return to the much criticized (by both constructivist and feminist therapists) APAs Diagnostic and Statistical Manual. The therapist may choose to mainly focus on the individual, in some cases the family, but there will be people with specific forms of distress that require some form of "subversion of patriarchal values" before the task of developing alternatives to those values can be embarked upon. Ironically, here we find DSM classification useful: People with the symptoms that can be traced back to emotional, physical or sexual abuse, such as rape victims, people with PTSD, and quite often people with an eating disorder will need some form of analysis of socially imposed constructions on power and of their place in the power hierarchy.

\section{References}

Brown, L. S. (1994). Subversive dialogues: Theory in feminist therapy. Basic Books.

Brown, L. S. (2010). Feminist therapy. APA Washington, D.C..

Brown, L. S. (2000). Discomforts of the powerless: Feminist constructions of distress. In R. A. Neimeyer, \& J. D. Raskin (Eds.), Constructions of disorder. APA, Washington, D.C..

Button, E. (1993). Eating disorders: Personal construct therapy and change. Chichester: Wiley. 
Caplan, P. J. (1995). They say you're crazy: How the world's most powerful psychiatrists decide who is normal? Reading, M.A.: Addison-Wesley.

Dimcovic, N., \& Winter, D. A. (unpublished manuscript). The mystery of bulimia: What lies behind the symptom? DSM-IV. APA. Foucault, M. (1978). The history of sexuality (Vol. 1). New York Pantheon.

Gergen, J. K. (2009). An invitation to social construction (2nd ed.). Sage.

Kelly, G. (1955). The psychology of personal constructs (Vols. 1\&2). London, Routledge.

Kelly, G. (1991). The psychology of personal constructs (Vols. 1\&2). London, Routledge.

Neimeyer, R. A. (1999). Constructivist psychotherapies: Features, foundations, and future directions. In R. A. Neimeyerand, M. J. Machoney (Eds.), Constructivism in psychotherapy. APA Washington, D.C..

Neimeyer, R. A., \& Raskin, J. D. (2000). On practicing postmodern therapy in modern times. In R. A. Neimeyer \& J. D. Raskin (Eds.), Constructions of disorder. APA, Washington, D.C..

Neimeyer, R. A. (2009). Constructivist psychotherapy. Routlede.

Orbach, S. (1978). Fat is a feminist issue. Arrow Books.

Pantony, K. L., \& Caplan, P. J. (1991). Delusional dominating personality disorder: A modest proposal for identifying some consequences of rigid masculine socialization. Psychologie Canadienne, 32, 110-133.

Pavlovic, J. (in press). Using constructs and discourses as tools for exploration and transformation of meaning.

Procter, H. (1996). The family constructsystem. In D. Kalekin-Fishman, \& B. Walker (Eds.), The construction of group realities. Krieger Publishing Company, Malabar, Florida.

Procter, H. (2009). The construct. In R. Butler (Ed.), On reflection: Emphasizing the personal in personal construct theory. Wiley, Chichester.

Procter, H. (in press). Developments in personal and relational construct psychology: Qualitative grids and the levels of interpersonal construing.

Raskin, J. D., Weihs, K. D., \& Morano, L. A. (2005). Personal construct psychotherapy meets constructivism: Convergence, divergence, possibility. In D. A. Winter, \& L. L.Viney (Eds.), Personal construct psychotherapy: Advances in theory, practice and research. Whurr Publshes, London and Philadelphia.

Suyemoto, K. L., \& Kim, G. S. (2005). Journey through diverse terrains: Multiple identities and social context in individual therapy. In M. P. Mirkin, K. L. Suyemoto, \& B. F. Okun (Eds.), Psychotherapy with women. The Guilford Press, New York London.

Tchudi, F. (1977). Loaded and honest questions: A construct theory view of symptoms and therapy. In D. Banister (Ed.), New perspectives in personal construct theory. London Academic Press.

Winter, D. A., \& Button, E. (2010). A personal construct perspective on controlling eating disorders. In S. Sassaroli, \& G. M. Ruggiero (Eds.), Cognitive therapy of eating disorders on control and worry. Nova Science Publishers Inc., New York. 